\title{
ABAHIA SE REVÉM: CONSIDERAÇÕES SOBRE A TRADUÇÃO DE FINNEGANS WAKE
}

\section{ABAHIA SE REVÉM: CONSIDERATIONS ON THE TRANSLATION OF FINNEGANS WAKE}

\author{
Vitor Alevato do Amaral \\ Universidade Federal Fluminense, Rio de Janeiro, Rio de Janeiro, Brasil \\ vitoramaral@,id.uff.br
}

\begin{abstract}
Resumo: Neste artigo, discutimos os desafios de se ler e traduzir Finnegans Wake (1939), de James Joyce (1882-1941). A primeira parte lida com o apelo do próprio romance para que se adote um novo paradigma de tradução capaz de torná-lo traduzível. A perspectiva de Joyce sobre a tradução de Finnegans Wake também é explorada. A segunda parte prioriza o trabalho de quatro tradutores de Finnegans Wake para o português brasileiro: Augusto de Campos, Donaldo Schüler, Dirce Watrick do Amarante e Caetano Galindo. As traduções de um curto excerto do texto de Joyce realizada pelos mencionados tradutores são objeto de análise. Suas visões sobre como traduzir a obra de Joyce também são levadas em consideração.
\end{abstract}

Palavras-chave: James Joyce; Finnegans Wake; Tradução

\begin{abstract}
In this article, we discuss the challenges of reading and translating Finnegans Wake (1939), by James Joyce (1882-1941). The first part of the article deals with the novel's urge to the adoption of a new translation paradigm in order to make itself translatable. Joyce's own perspective of the translation of Finnegans Wake is explored. The second part focuses on the work of four translators of Finnegans Wake into Brazilian Portuguese: Augusto de Campos, Donaldo Schüler, Dirce Watrick do Amarante and Caetano Galindo. The translations of a short excerpt from Joyce's text by the abovementioned translators are analyzed. Their views of translating Joyce's work are also taken into consideration.
\end{abstract}

Keywords: James Joyce; Finnegans Wake; Translation 


\section{Ler e traduzir Finnegans Wake}

O escritor tcheco Adolf Hoffmeister publicou, em 1932, uma tradução de "Anna Livia Plurabelle", oitavo capítulo de Finnegans Wake (1939), para sua língua, realizada em parceria com Vladimír Procházka e Marie Weatherall. A obra, à época ainda incompleta, era chamada provisoriamente de Work in Progress. Como explica Michelle Woods (2005), antes que a tradução completa viesse a lume, Hoffmeister e Procházka publicaram um fragmento do capítulo acompanhado de uma introdução em que os dois afirmavam:

Work in Progress nunca será inteiramente traduzido, pois ninguém poderia completar a tarefa, dado o tempo médio de vida de uma pessoa... Estamos totalmente cientes de que estamos fazendo um trabalho que não será compreendido nem recompensado... Nossa tradução nunca será um espelho preciso do original. Porém... sabemos que tentamos uma tradução de bela poesia, uma tradução que expande a abóbada celeste sobre o mundo do homem ${ }^{1}$ (HOFFMEISTER; PROCHÁZKA apud WOODS, 2005) ${ }^{2}$.

Os tradutores lamentam que o resultado de seu trabalho não seja espelho do original. "Tentar uma tradução de bela poesia" aparece como remédio ao mal de não se ter conseguido chegar ao resultado do espelho, quando, na verdade, o espelho é o mal. O bom resultado do trabalho certamente deveu-se, entre outras coisas, ao fato de os tradutores para o checo terem optado por uma tradução poética em lugar do espelhamento. A tradução de "Anna Livia Plurabelle", feita por Hoffmeister, Procházka e Weatherall chegou mesmo a ser considerada "uma das mais criativas performances na história da tradução tcheca" 3 (GRMELA apud O’NEILL, 2018, p. 28). Provocativamente, poderíamos perguntar se não é melhor dizer na história da literatura tcheca ou da língua tcheca.

Hoffmeister também publicara em duas partes, nos anos de 1930 e 1931, o relato de uma conversa com Joyce, ocorrida em agosto de 1930, em Paris. Por ela sabemos que o próprio Joyce acreditava que Finnegans Wake fosse intraduzível, mas intraduzível em termos de espelhamento. Para ele, a opção à tradução seria a poesia. Eis o que disse Joyce:

É possível transformá-lo [Finnegans Wake] em poesia — poetizá-lo com a maior liberdade poética que puder. Work in Progress não está escrito em inglês, ou francês, ou checo, ou irlandês. Anna Livia não fala qualquer dessas línguas, ela fala a língua de um rio ${ }^{4}$ (JOYCE; HOFFMEISTER, 2005).

Minutos depois, Joyce foi assertivo: "Não quero ser traduzido [...]. Estou lhe dando toda a liberdade possível para a transformação das palavras" "JOYCE; HOFFMEISTER, 2005). A autorização concedida por Joyce para a metamorfose de Finnegans Wake em outra língua diverge da postura que assumiria ao abordar a possível tradutora de Ulysses para o dinamarquês alguns anos mais tarde: "sou James Joyce. Entendo que é a senhora que vai

\footnotetext{
1 'The complete Work in Progress, will never be translated, because no one would be able to translate it, taking into account the average life-span... We are fully aware that we are doing work which will not be understood and will go unrewarded... Our translation will never be a precise mirror of the original. But...we are clear that we have attempted a translation of beautiful poetry, one which extends the vault of the sky over the world of man."

2 Todas as traduções realizadas para este artigo são de nossa autoria.

3 "one of the top creative performances in the whole history of Czech translation".

4 "It is possible to make it into poetry-poeticize it with the greatest poetic freedom that you can give it. Work in Progress is not written in English or French or Czech or Irish. Anna Livia does not speak any of these languages, she speaks the speech of a river".

5 "I do not want to be translated [...]. I am giving you every possible freedom in the transformation of words".
} 
traduzir Ulysses e vim de Paris para lhe dizer que não altere uma só palavra"6 (ELLMANN, 1983, p. 692).

Ao mesmo tempo em que podemos aceitar a liberdade que Joyce nos concede, devemos, hoje, subverter a oposição entre tradução e poesia e entender a tradução como poesia, isto é, como criação. Joyce nos pediu para não traduzir, mas para fazer poesia. Nós devemos obedecer desobedecendo, isto é, fazer poesia traduzindo.

Em entrevista recente ${ }^{7}$ de Fritz Senn (SENN; AMARAL, 2019), exímio leitor de Joyce, notamos um leitor triste ou irritado por ter falhado com Finnegans Wake, segundo ele próprio. Senn se pergunta como podem os pesquisadores escreverem sobre uma obra da qual conhecem tão pouco e da qual ele mesmo diz não entender mais do que trinta por cento. A pergunta que nos parece cabível diante dessa provocação é também uma provocação: podemos ler Finnegans Wake com as mesmas ferramentas filológicas que usamos para ler Ulysses?

No entanto, Senn acentua a necessidade de se traduzir Finnegans Wake justamente porque a obra não pode ser traduzida - pelo menos nos termos em que normalmente entendemos a tradução. Nela, os paradigmas tradutórios são outros. O próprio crítico, de forma bem-humorada, já tinha afirmado que “quando alguém em público diz como 'nós' ou 'o leitor' reagem a uma certa passagem, com frequência eu me sinto tentado a levantar e pedir uma correção: 'o leitor com a possível exceção de Fritz Senn"" (SENN, 2007, p. 107). Ele parece voltar-se contra a tentativa de se adivinhar ou controlar os efeitos do texto sobre o leitor, quando efeitos dependem de sentidos, e nenhum dos dois estão determinados antes da efetiva leitura. Em se tratando de Finnegans Wake, ele destaca a possibilidade de as traduções produzirem efeitos - jamais determinados de antemão - nos leitores, e aponta-os como recurso fundamental à tradução.

Diferentemente do que parece ocorrer na tradução de Ulysses, ou da maior parte de Ulysses, Finnegans Wake deixa a sensação de que estamos diante de um amálgama tão forte entre forma e sentido que nos vemos diante da não-opção tradutória, isto é, não enxergamos para aquilo outra opção senão aquilo mesmo. Por isso, Senn enfatiza os efeitos decorrentes da leitura. Vejamos um exemplo de nossa escolha em que se podem acentuar, na tradução, alguns aspectos sonoros do texto de partida que podem ajudar na produção desse efeito a que, salvo engano, Senn se refere:

Lowly, longly, a wail went forth. Pure Yawn lay low. On the mead of the hillock lay, heartsoul dormant mid shadowed landshape, brief wallet to his side, and arm loose [...] $(F W 474.1-3)^{9}$

Ligeiro, longo, um lamento elevou-se. Puro Yawn levemente aleitado. No limpo campo da colina aleitado, fundamente adormecido em meio à ensombrecida vista, sacola de epístolas ao lado, e braço desleixado [...] (Nossa tradução)

Na maioria dos casos, "ligeiro" não seria a primeira opção para se traduzir lowly, nem "elevou-se" para went forth, nem "aleitado" para lay low. Mas, a repetição dos sons líquidos pode produzir efeitos, embora não saibamos exatamente quais. As sibilantes de heartsoul, shadowed landshape, side e loose também dão azo a "adormecido", "ensombrecida", "sacola" e "braço". E, por fim, em nosso dialeto carioca, os chiados dos

\footnotetext{
6 "I am James Joyce. I understand that you are to translate Ulysses, and I have come from Paris to tell you not to alter a single word".

${ }^{7}$ A entrevista será publicada na edição de dezembro da revista Qorpus (UFSC).

8 "The reader with the possible exception of Fritz Senn".

${ }^{9}$ Seguimos a convenção dos estudos joycianos de citar Finnegans Wake pela abreviação $F W$ seguida de página e linha do texto, que são as mesmas em quase todas as edições da obra.
} 
esses de "vista" e "epístolas" se casam com os de shadowed landshape. Essa é uma proposta de tradução que pretende criar um novo texto para Finnegans Wake em língua portuguesa por meio da tradução. O texto de partida e o de chegada, frente a frente, certamente se estranharão; pois não há espelhamento possível.

Realmente, Finnegans Wake, como escreveu Len Platt (2012, p. vi-vii), "é muito mais do que simplesmente "difícil"" ${ }^{10}$. E, por falar em dificuldade, Finnegans Wake é a antítese do que elabora George Steiner (1978) em seu ensaio "On Difficulty" (Sobre a dificuldade), no qual explica que, mesmo quando chegamos a entender algo difícil, não há garantia de que nos relacionemos com o que foi entendido. Por outro lado, T. S. Eliot (1934, p. 238) afirmava que "a poesia genuína pode comunicar antes de ser entendida"11. Portanto, simplificando essas duas sofisticadas visões, é possível entendermos para depois nos relacionarmos, como em Steiner, e nos relacionarmos para depois entendermos, como em Eliot. Mas, como Finnegans Wake não é "simplesmente 'difícil"', nenhuma dessas alternativas parece ser a que melhor se aplica a seu caso, pois nele não pode haver entendimento sem que haja relação (ou comunicação, para ficarmos mais próximos de Eliot). Em Finnegans Wake, começamos a entender quando nos relacionamos, e ambos, entendimento e relacionamento, prosperam juntos. A intensa relação do que com o como não permite que se dissociem as esferas do entendimento e do relacionamento.

De certo modo, Finnegans Wake é menos hermético do que Dubliners (1914). Sabemos que podemos "abrir" os contos, mas o inclassificável Finnegans Wake já está aberto; temos que ir, cada leitor a seu modo, nos fechando nele. Lemos o livro, fruímos do livro e, ao traduzi-lo, devemos tentar fazer com que outras fruições sejam possíveis em outras línguas. $\mathrm{O}$ efeito provocado é resultado do trabalho criador (não meramente criativo) feito na tradução por meio de algo que ao menos se assemelhe a um "projeto estético radical", para usar a expressão de Haroldo de Campos (1981, p. 184), necessário para se traduzir a última grande obra de Joyce.

No ideal de Walter Benjamin (2011, p. 117), a tradução apenas toca o sentido do texto. Daí que, na reflexão de "A tarefa do tradutor", "traduções [...] revelam-se intraduzíveis [...] devido à excessiva fugacidade com que o sentido a elas adere" (p. 118). Isso revela um dado fundamental para compreendermos o pensamento benjaminiano: o de que o sentido, embora não seja o essencial, jamais pode ser ignorado pelo tradutor, pois não deveria haver tradução se não houvesse sentido suficiente a ser tocado.

Pois bem, que sentidos tocar em Finnegans Wake? Tudo no livro encanta ou apavora pela enorme possibilidade de sentidos que encerra. Se, como escreveu Platt (2012, p. xxii),

a capacidade de Finnegans Wake para se comunicar é constantemente atacada [...] não é que Wake não tenha sentido [mas] um número exagerado de possibilidades concorrentes que vão de encontro às expectativas criadas pela sede de conhecimento, que é, ela mesma, uma característica de $W a k e^{12}$.

Em outras palavras, ainda citando Platt (p. xxii), Finnegans Wake é "uma assombrosa interferência em nossa cultura do que seja ler e entender" ${ }^{\prime 13}$.

Esse exagero de possibilidades demandaria do leitor e do tradutor ideal "uma insônia ideal"14 (FW 120.13-14), mas também, como diria Umberto Eco (1995, p. 109-110), “uma

\footnotetext{
10 "This is much more than simply "difficult"".

11 "genuine poetry can communicate before it is understood".

12 "the capacity of the Wake for communication is constantly under siege [...] it is not that the Wake has no meaning [but] too many competing possibilities which run entirely counter to expectations raised by the will to knowledge, equally so characteristic of the Wake".

13 "an astonishing interference in our cultures of reading and understanding".

14 "an ideal insomnia".
} 
infinita competência enciclopédica, superior à de James Joyce enquanto autor empírico", ou seja, o leitor ideal apreenderia até mesmo "alusões e conexões semânticas"15 que o próprio Joyce não foi capaz de captar. Esse leitor - e tradutor - não existe, nem existirá em modalidade humana. Definitivamente, é como tarefa humanamente imperfeita que devemos encarar a leitura e a tradução de Finnegans Wake.

Há um áudio gravado de Frank O'Connor sobre uma conversa que tivera com Joyce nos anos 1920 em que Joyce lhe perguntou: "o senhor não é de Cork? [...] Lá ainda chamam um penny de lob?" Mas, O'Connor explica na gravação, em Cork o termo usado para um pêni é lop e não $l o b^{16}$ (O'CONNOR, 1996). Ao menos P. W. Joyce (1910, p. 287), em seu English as We Speak It in Ireland, parece endossar O'Connor, já que seu livro registra lob como "uma quantidade, especialmente de dinheiro ou qualquer produto de valor" ${ }^{\text {"17, mas não }}$ especificamente como um pêni. Joyce, como bom inventariante que era, deve ter feito com que engolíssemos alguns lobs por lops. Sem que isto sirva de justificativa à negligência de algum tradutor, ainda temos que reconhecer o quanto pode ser difícil detectar um erro de Joyce em Finnegans Wake - se bem que Stephen Dedalus já tinha explicado em Ulysses que gênios não erram (JOYCE, 1986, p. 156) - pois, na obra-limite de Joyce, o erro tende a perder-se em um texto cujos paradigmas de certo e errado ele mesmo, em larga medida, funda.

No capítulo 15, por exemplo, lemos "Oyessoyess!" ( $F W$ 488.19), que na primeira edição aparecia como "Oessoyess!". Só temos certeza de que se trata de um erro tipográfico porque o próprio autor o localizou e incluiu entre centenas de outros problemas posteriormente enviados à Viking Press e à Faber and Faber. A Viking, em 1945, publicou um livreto de dezesseis páginas contendo as correções, que era entregue aos compradores do livro. Em sua errata, Joyce também corrigiu "from norning rice to nightmale" para "from morning rice to nightmale" ( $F W$ 485.26), mas nos permitimos perguntar quem, antes de suspeitar de um erro, não suspeitaria de um uso inteligente das palavras por parte do escritor. Somemos a isso o fato de que até hoje algumas edições da obra ainda não incorporaram os elementos da errata e começaremos a medir a dimensão do problema editorial que tem consequências diretas na tradução.

A edição ideal está tão longe de pôr fim à instabilidade do texto de Finnegans Wake - e de outras obras de Joyce - que a James Joyce Quarterly, principal periódico sobre Joyce, em recente número (vol. 55, n. 3-4), mudou sua política editorial e substituiu o termo "edições-padrão" (standard editions) por "edições preferenciais" (preferred editions). Com isso, se antes apenas as edições de Finnegans Wake publicadas pela Viking Press e da Faber and Faber podiam ser citadas nas contribuições ao periódico, agora outras duas (a da Oxford World's Classics, editada por Finn Fordham, Robbert-Jan Henkes e Erik Bindervoet, e a da Penguin Classics, intitulada The Restored Finnegans Wake, editada por Danis Rose e John O'Hanlon) também são aceitas. A decisão por "uma nova e muito maior flexibilidade na política de citação" ${ }^{18}$, segundo Sean Latham (2018, p. 277), editor do periódico, foi amparada nas opiniões dos membros do conselho editorial e de uma subcomissão especialmente designada para o tema, formada pelos especialistas em Joyce Michael Groden, Sam Slote, Valérie Bénéjam. No mesmo número, Slote (2018, p. 405) assina um estudo relevante e didático sobre a "confusão textual"19 de Finnegans Wake, apontando problemas mesmo na edição da Faber and Faber de 1975, que, no ano de lançamento, Clive Hart (apud SLOTE,

\footnotetext{
15 "an infinite encyclopedic competence, superior to that of the empirical author James Joyce"; "allusions and semantic connections".

16 “Aren't you from Cork? [...] Do they still call a penny a lob?".

17 "a quantity, especially of money or of any valuable commodity".

18 "a new, far more flexible policy for citation".

19 "textual mess".
} 
2018, p. 408) afirmou ser "a mais exata" 20 de todas. Uma solução para o problema, segundo Slote (2018, p. 408), seria editar o texto do início, o que fizeram Danis Rose e John O'Hanlon e o que estão fazendo Finn Fordham, Robbert-Jan Henkes e Erik Bindervoet.

\section{Finnegans Wake no Brasil, por seus tradutores}

Na primeira parte do texto, tratamos de alguns desafios à leitura e tradução de Finnegans Wake. Nesta segunda parte, discorreremos sobre algumas traduções da obra no Brasil e os pontos de vista de seus tradutores.

Entre os primeiros desbravadores de Finnegans Wake estão os irmãos Haroldo e Augusto de Campos, que publicaram, em 1962, o Panaroma do 'Finnegans Wake', revisto e ampliado até a quarta edição (2001). O último livro de Joyce tem uma tradução completa para o português, feita por Donaldo Schüler e publicada em cinco volumes, entre 1999 e 2003. Em 2018, Dirce Waltrick do Amarante publicou "Finnegans Wake" (por um fio). Caetano Galindo, tradutor de várias obras de Joyce, incluindo Ulysses, já comentou sobre seu projeto de tradução da obra e chegou a publicar dois fragmentos de seu trabalho. Por último, um grupo de nove tradutores ${ }^{21}$, sob a coordenação de Amarante, está retraduzindo Finnegans Wake.

Em esclarecedora entrevista concedida ao Jornal da Tarde (30/01/1982) reproduzida na revista Ilha do Desterro (1984), Augusto de Campos conta que entrou em contato com a obra de Joyce em 1949, por meio do artigo de Louis Gillet "A propósito do Finnegans Wake a extraordinária aventura de James Joyce", publicado no Jornal de São Paulo (30/10/1949). Segundo Campos (1984, p. 25),

eram raras, em nosso meio, as referências mais profundas à sua obra [de Joyce] e em particular ao Finnegans Wake, publicado em 1939. Os escritores das gerações modernistas que frequentavam os suplementos literários - os suplementos eram muito importantes naquela época - tinham formação essencialmente francesa.

Os irmãos Campos começaram a divulgar suas traduções de fragmentos de Finnegans Wake no Jornal do Brasil ainda em 1957. A primeira edição do Panaroma (a palavra é retirada do próprio Finnegans Wake) é de 1962 e reúne onze fragmentos traduzidos, incluindo os publicados no Jornal do Brasil, e apresentados em formato bilíngue. Não há dúvida de que a primeira edição do Panaroma é um marco na tradução literária no Brasil. Ela representa para nossa tradição tradutória uma ousadia que alimentaria a geração seguinte e ajudaria a confirmar o Brasil como um país importante no que diz respeito a traduções de Joyce. A obra tida por muitos como ilegível e intraduzível encontrou na língua portuguesa do Brasil tradutores que aceitaram o desafio da tradução realizando "ginástica com a palavra" (CAMPOS, 1962, p. 7) no mais alto nível.

A indissociabilidade entre forma e conteúdo, que Samuel Beckett (1972, p. 14) reconhecera e expressara ao afirmar que a escrita de Joyce não é sobre alguma coisa, mas é a própria coisa, o que explica parcialmente por que o sentimento de intraduzibilidade da obra tenta impor-se, como apresentamos na primeira parte deste artigo, foi assim formulada pelos dois tradutores brasileiros:

No Finnegans Wake abole-se o dualismo fundo-forma, em prol de uma dialética perene de conteúdo-e-continente, de um onipresente isomorfismo: se o entrecho é fluvial, nomes de rios se imbricam nos vocábulos, criando um circuito reversível de reflexos do nível temático ao nível formal”' (CAMPOS, 1962, p. 8).

\footnotetext{
20 "the most accurate".

21 André Cechinel, Afonso Teixeira, Aurora Bernardini, Daiane Oliveira, Dirce Waltrick do Amarante, Fedra Rodríguez, Sérgio Medeiros, Vinícius Alves e Vitor Alevato do Amaral.
} 
A tradução de Donaldo Schüler, única completa em língua portuguesa, foi publicada em cinco volumes bilíngues e anotados, entre 1999 e 2003. Um detalhe da edição que reflete um cuidado editorial inestimável é o respeito à paginação e ao número de linhas por página usuais nas edições originais da obra. Os volumes têm duas paginações: a do cabeçalho se reinicia a cada volume, mas a do rodapé, entre colchetes, vai da 3 a 628 ininterruptamente, do primeiro ao quinto volume. Em comunicação por e-mail, o tradutor informou que o texto fonte foi o da editora Faber and Faber, de 1939.

O convite para a tradução de Finnegans Wake partiu da Casa de Cultura Guimarães Rosa, "uma sociedade psicanalítica lacaniana" (AMARANTE; TÁPIA, 2018, p. 79). Schüler deu um "passeio pelo romance" antes de assumir a tarefa, ciente de que se entra na "floresta escura" do livro sem as mãos de um guia, tendo ingressado "pela fenda que se abre entre o segundo e o terceiro capítulo" (p. 79-80). “Ópera, película ou romance?”, ele pergunta e responde: "Joyce acavala tudo" (p. 80). Schuler sai do livro, descansa, relembra, lê as anotações e "começa a leitura sistemática, a tradução sistemática, aparelhado de tudo o que p[o]de alcançar" (p. 100).

As recentes reflexões de Schüler sobre sua tradução nos fazem retornar às reflexões iniciais deste texto: como ler Finnegans Wake? Como traduzi-lo? Para Schüler, pode-se afirmar que

só os textos ilegíveis merecem ser lidos. O ilegível reside no estranho, recusa e provocação, revestido por palavras. Textos ilegíveis convocam o leitor para que flua o que no texto se concentrou. Textos legíveis traem porque não apresentam nada. Cansam por nos obrigarem a navegar no óbvio (AMARANTE; TÁPIA, 2018, p. 102-103).

A primeira nota de leitura da tradução de Schüler se chama "Beirando ABahia". A nota é esclarecedora porque afasta a possível conclusão segundo a qual o trabalho do tradutor teria pretendido simplesmente abrasileirar Joyce. Leiamos parte da nota:

\begin{abstract}
Philipe Lavergne traduz past Eve and Adam's com pass' notre Adam. Ouve-se em notre Adam o nome da catedral parisiense Notre Dame, ligada ao pai da humanidade Adam. A tradução é feliz. Tira, entretanto, a ação da Irlanda e a leva a Paris o que, aliás, não contradiz a intenção universalizadora de Joyce. Os topônimos modificados perdem rigor denotativo. Se estamos interessados em fazer com que o rio universal atravesse o Brasil, podemos substituir a igreja dublinense por uma igreja brasileira, Nossa Senhora do Ó, por exemplo. Se quisermos incorporar nela o princípio masculino, a exemplo do que fizeram Joyce e Lavergne, poderemos dizer Nossenhora do Ohmem (SCHÜLER, 1999, p. 92).
\end{abstract}

A presença d'ABahia, com " $h$ ", logo no início do livro, tanto abrasileira o texto, isto é, aproxima-o da realidade do leitor brasileiro-alvo, quanto universaliza a Bahia ao transformá-la em ABahia e transpantá-la para o mundo criado por Joyce. Além disso, a Bahia e o Castelo de Howth podem muito bem integrar o mesmo sonho. Já podemos notar que a lição de Fritz Senn sobre como Finnegans Wake impõe uma quebra de paradigmas no trabalho da tradução nos leva igualmente a ter que reexaminar os conceitos de domesticação e estrangeirização consagrados nos Estudos da Tradução.

Em 2018, Dirce Waltrick do Amarante publicou "Finnegans Wake" (por um fio). Amarante já havia publicado Para ler "Finnegans Wake" de James Joyce (2009), em que se encontra a tradução de "Anna Livia Plurabelle", e James Joyce e seus tradutores (2015), que também trata de Finnegans Wake. Para essa tradução, a tradutora esclarece que utilizou "várias edições de Finnegans Wake", incluindo a que está disponível online em www.finwake.com (AMARANTE, 2018, p. 181). 
Ao puxar da obra um fio narrativo, povoado de "passagens poeticamente exemplares e conhecidas [...] e pontos de luz, sentenças talvez menos inventivas, portanto mais claras que outras tantas do livro", a tradutora nos conduz por um "fio narrativo" que dá conta de sua "errância", mas que é provisório, pois "numa próxima ele pode mudar", e não deve impedir os leitores de encontrarem seus próprios percursos (AMARANTE, 2018, p. 175-176).

Amarante "encurta" a obra de Joyce. Porém, faz isso menos para servir de introdução do que para demonstrar suas inúmeras possibilidades de leitura. Ela não foi a primeira a apresentar uma versão mais curta de Finnegans Wake. Anthony Burgess já o fizera em 1966 com seu A Shorter "Finnegans Wake", de cujo prefácio, ao contrário da intenção de Amarante, se depreende o propósito de oferecer uma versão mais acessível do livro capaz de encorajar o leitor a ir ao texto completo em outro momento. Burgess $(1973$, p. 5) até mesmo alerta para o perigo de que, ao se "puxar um só fio" de Finnegans Wake possa-se "desfazer todo o tecido" 22 , o que não o impediu de "reduzir o livro a pouco mais de um terço de seu tamanho original". A tradutora brasileira, com seu fio puxado, prova que Burgess estava errado, ou que pelo menos não entendeu que Finnegans Wake clama pelo desfio e pelo desvio, e que depende deles para sobreviver.

Caetano Galindo, tradutor de várias obras de Joyce, incluindo Ulysses, já comentou sobre seu projeto de tradução da obra e chegou a publicar dois fragmentos de seu trabalho. Um está no caderno "Ilustríssima" da Folha de São Paulo (24/11/2013) e corresponde a parte do conteúdo das páginas 21 a 23 do livro. A tradução é antecedida por uma nota do jornal em que se destaca uma observação do tradutor: "Finnegans Wake não existe para ser exatamente 'entendido'. Leia em voz alta, brinque um pouco com o texto e deixe que ele te ensine a sua língua própria" (JOYCE, 2013). O outro fragmento pode ser encontrado na revista Circuladô (n. 5, 2016) e cobre as páginas 104 a 107 do original. Nas palavras de Galindo, "traduzir o Wake é decidir como traduzir o Wake", e sua decisão foi especialmente pautada por "sonoridade, ludismo, humor", postura de um tradutor "de certa forma 'liberado' pela postura 'liberal' e quase 'libertina' que o próprio Joyce adotou ao comentar, por exemplo, a tradução de um fragmento do romance ao italiano" (JOYCE, 2016, p. 66). A postura de Galindo encontra abrigo também nas palavras de Joyce ao tradutor tcheco, já referidas na primeira parte do texto. Por e-mail, Galindo afirmou que tem utilizado como fonte a edição da Penguin, mas que pode vir a lançar mão da edição restaurada de Danis Rose, que mencionamos na primeira parte do artigo, para o fechamento de seu trabalho.

Analisemos as três linhas que abrem Finnegans Wake nas traduções de Augusto de Campos, Schüler, Amarante e Galindo:

riverrun, past Eve and Adam's, from swerve of shore to bend of bay, brings us by a commodius vicus of recirculation back to Howth Castle and Environs ( $F W 3.1-3)$.

riocorrente, depois de Eva e Adão, do desvio da praia à dobra da baía, devolve-nos por um cômodo vicus de recirculação de volta a Howth Castle Ecercanias (CAMPOS, 1962, p. 15, trad. Augusto de Campos).

riocorrente, depois de Eva e Adão, do desvio da praia à dobra da baía, devolve-nos por um commodius vicus de recirculação devolta a Howth Castle Ecercanias (CAMPOS, 2001, p. 41, trad. Augusto de Campos).

rolarrioanna e passa por Nossenhora d'Ohmem's, roçando a praia, beirando ABahia, reconduz-nos por cominhos recorrentes de Vico ao de Howth Castelo Earredores (JOYCE, 1999, vol. 1, p. 31, trad. Schüler).

\footnotetext{
22 "to pull a single thread will unravel the entire fabric".
} 
correorrio, após Adão e Eva, da contornada costa à encurvada enseada, nos leva por um commodius vicus recirculante de volta para Howth Castle e Entornos (JOYCE, 2018, p. 19, trad. Amarante).

Ribeiranda, em pós de Eva e de Adão, do encolho da costa à dobrada baía, nos devolve por comódico vico recirculatório a Howth, seu Castelo Ealredores (trad. Galindo $)^{23}$.

A começar por Campos, notamos que ele revisa a tradução do trecho selecionado para análise após a primeira edição do Panaroma. O toque latinizante de commodius, criado pela retirada da segunda letra "o" do adjetivo inglês commodious (cômodo, conveniente) no texto de partida, é recuperado nas edições subsequentes. Ele se acentua pela proximidade sonora e sintagmática com vicus (segundo o Shorter Oxford English Dictionary, na arqueologia, tratando-se do Império Romano, pode referir-se a uma aldeia), palavra de origem latina dicionarizada em inglês. Entre as traduções brasileiras destacadas, apenas Campos e Amarante preservam intocado o sintagma commodius vicus. Galindo opta por "comódico vico", que atenua o eco latino, mas destaca o nome de Giambattista Vico, figura fundamental para a construção de Finnegans Wake, que será mais à frente retomada, sem deixar de garantir o elemento romano "vico", dicionarizado pelo Grande Dicionário Houaiss como, entre outras coisas, "bairro de uma cidade" e "prédio rústico, entre os romanos". A repetição (quase rima interna) de "ico" também valoriza a camada sonora do trecho e emula a semelhança entre "ius" e "icus" do texto de partida. Schüler, por sua vez, opera uma transformação mais radical ao utilizar "cominhos recorrentes de Vico". Não só o nome do filósofo italiano salta a olhos vistos, mas os termos do commodius vicus joyciano são separados pelo adjetivo "recorrentes", capaz de salientar a presença das correntes de um rio e reiterar o uso do prefixo -re, já usado em "reconduz-nos". Adicionalmente, notamos o tempero brasileiro da tradução pela presença do "cominho", cumpridor do papel de quebrar a provável expectativa do leitor em ler "caminho".

A tradução de "Eve and Adam's" é sempre espinhosa na língua portuguesa. O elemento mais óbvio em "Eve and Adam's" é a convivência dos nomes de duas figuras míticas associadas ao pecado com o nome popular de uma igreja em Dublim, Igreja de Adão e Eva (na verdade, a Igreja da Imaculada Concepção). Sabemos pela já mencionada explicação que Schüler tentou manter essa convivência ao lançar mão de uma saída inspirada na tradução francesa, sem lidar com o apelo dos nomes de Adão e Eva. Ao lado disso, também é notável a inversão do par culturalmente consagrado Adam and Eve, que se transforma em Eve and Adam, fazendo com que o nome feminino anteceda o masculino, uma precedência que pode produzir sentidos no texto de Joyce. À exceção da saída encontrada por Schüler, "Nossenhora d'Ohmem's", as de Amarante e Galindo parecem ter sido guiadas, entre outras coisas, pelo fito de evitar o cacófato formado por "Eva e Adão". Amarante desfaz a inversão joyciana e usa o popular "Adão e Eva" (tão popular quanto o nome da igreja em Dublim), enquanto Galindo mantem a ordem original, mas implanta uma preposição que habilmente impede o cacófato: "Eva e de Adão". Apenas Campos, mesmo tendo tipo duas oportunidades, não desistiu de usar "Eva e Adão".

Também podemos ressaltar as maneiras inventivas que os quatro tradutores encontraram para manter a alusão à personagem Humphrey Chimpden Eearwicker presente nas iniciais maiúsculas de "Howth Castle and Environs". Ao contruírem as saídas "Howth Castle Ecercanias", "Howth Castelo Earredores", "Howth Castle e Entornos" e "Howth, seu Castelo Ealredores", eles conservaram a primeira das sequências de palavras cujas iniciais formam HCE, uma das marcas do texto de Finnegans Wake.

\footnotetext{
${ }^{23}$ Agradecemos a Caetano Galindo pelo envio deste trecho de sua tradução em curso.
} 
Temos à disposição o resultado de cinco leituras diferentes. Essas leituras facilmente se desdobram ao se relacionam com traduções para outras línguas e com a fortuna crítica existente, além de demonstram que a análise da tradução de um curto trecho de Finnegans Wake pode se tornar infinita. Esperamos que os aspectos das cinco traduções que foram salientados tenham dado mostra tanto do desafio de se traduzir a obra quanto da capacidade desses quatro tradutores para dialogar com ela e aproveitar as possibilidades de criação a ela inerentes. $\mathrm{O}$ aprofundamento desse tipo de exercício de crítica deve se estender para a análise da organicidade de cada tradução, que não pode ser avaliada apenas por amostragem, principalmente uma tão módica.

Vale a pena, ainda, comentar a tradução do título Finnegans Wake. Até 1938, Joyce guardou segredo quanto ao título de sua obra, chamando-a apenas de Work in Progress (obra em progresso, ou em andamento, ou em curso, como prefiro, lembrando o curso de um rio). $\mathrm{O}$ título da balada da qual Joyce retirou o nome do livro é Finnegan's Wake, com apóstrofo. Ao retirar retirá-lo do título, Joyce ampliou as possibilidades de sentidos de seu título e, por conseguinte, seu livro. A tradução italiana, a francesa e a argentina, por exemplo, mantêm a forma original. No Brasil, com o Panaroma, o título ganhou nova possibilidade, Finnicius revém, aproveitado por Schüler, que assim se expressa sobre ele:

\begin{abstract}
Ouvem-se em Finnegans Wake sonoridades do idioma que uniu o Ocidente, o latim do império romano: finis (fim) aposto a again para anunciar a circularidade viconiana. O componente latino induz os irmãos Campos à tradução Finnicius Revém. Ao passar pelo francês (rêve - sonho), o título traduzido sustenta a substância onírica do romance. O tradutor romanceia na esteira do original. Oportuno é recordar, na composição do título, a expressão latina fines fluviorum, as desembocaduras dos rios. Podemos ignorar fin (fim), substantivo francês que rima com revém, vínculo sonoro de princípio e conclusão? (SCHÜLER, 1999, p. 15-16).
\end{abstract}

O título dos irmãos Campos é um achado. Ele ainda consegue reproduzir em português um equivalente ao lapso mais comum ao se escrever o título em inglês: se no original o título de Joyce costuma ganha um impertinente apóstrofo (Finnegan's), no português ele ganha um discreto acento (Finnícius). Acreditamos que esse tenha sido um ganho não pensado, mas é inegável que por instinto tendemos a empregar o apóstrofo de posse em inglês assim como, por ouvirmos Vinícius em Finnicius, tendemos a empregar o acento agudo no português.

Apresentamos uma nova proposta de título em português: Finnegan rivolta. Em "Finnegan", está o sobrenome (de Tim Finnegan) e a alusão ao fim (francês fin). A ambiguidade de wake (substantivo: velório ou despertar; verbo: velar ou despertar), encontrase em "rivolta", que é próximo do português "revolta", por sua vez também substantivo e verbo. $\mathrm{O}$ eco do italiano na segunda palavra do título substitui o sonho (rêve) do já clássico "revém" por um retorno alusivo ao italiano Giambattista Vico, figura central para Joyce em Finnegans Wake. Quem sabe, ainda, "rivolta" não faça os leitores caírem no lapso de escrever "revolta", emulando o problema criado pelo apóstrofo em inglês (Finnegan's) e pelo acento agudo em português (Finnícius)? Por fim, se rêve não se encontra em "rivolta", naveguemos por rive, riverain, rivière. E, riverrun!

\title{
Considerações finais
}

Finnegans Wake não tem propriamente um ponto de partida. Na cultura em que foi escrito, lê-se da esquerda para a direita, de cima para baixo. Essas duas regras, Joyce não quebrou. Quanto ao ponto de entrada, esse, os leitores podem escolher, dada a circularidade 
da obra: "O livro realmente não tem início ou fim"24, escreveu Joyce a Harriet Shaw Weaver em 8 de novembro de 1926 (JOYCE, 1975b, p. 314).

Finnegans Wake nos absorve e nos absolve de todo pecado. Só não nos absolve do pecado da falta de ousadia na leitura e na tradução. Afirmamos, mesmo sem contar com a absolvição de alguns estudiosos, que o tradutor do texto investido de grande valor estético dá o passo antes de haver ponte. O passo é estético; a ponte é cultural. Na tradução de Finnegans Wake, aquele pode vir antes desta - e não precisa vir necessariamente em função desta. $\mathrm{O}$ passo do tradutor não se deixa levar pela relativa segurança da ponte erguida pelo imperativo da comunicação intercultural. A ponte é que se vai construindo em obediência ao passo, sempre, nesse caso, para dentro do abismo. Mas, não se preocupem, o tradutor é sempre salvo, na última hora, para usar a expressão de Joyce, por "cada leitor inteligente" ${ }^{25}$ (JOYCE; HOFFMEISTER, 2005).

Como ler e como traduzir Finnegans Wake? Não há resposta definitiva. Mas podemos aprender observando as maneiras com que ele tem sido lido e traduzido para, a partir delas, apresentarmos novas propostas. Fiquemos por aqui, então, com as lições que aprendemos com Schüler - quanto mais ilegível, melhor - e com Senn - quanto mais intraduzível, melhor.

\section{Referências}

Amarante, Dirce Waltrick do. Para ler "Finnegans Wake” de James Joyce. São Paulo: Iluminuras, 2009.

Amarante, Dirce Waltrick do. James Joyce e seus tradutores. São Paulo: Iluminuras, 2015.

Amarante, Dirce Waltrick do. "Posfácio". In: Amarante, Dirce Waltrick do. "Finnegans Wake” (por um fio). São Paulo: Iluminuras, 2018, p. 165-181.

Amarante, Dirce Waltrick do; Tápia, Marcelo (Orgs.). Donaldo Schüler: entrevista. Curitiba: Medusa, 2018.

Benjamin, Walter. "A tarefa do tradutor". In: Benjamin, Walter. Escritos sobre mito e linguagem. (1915-1921). Jeanne Marie Gagnebin (org.). Tradução de Susana Kampff Lages. São Paulo: Duas Cidades/Editora 34, 2011, p. 101-119.

Beckett, Samuel. "Dante... Bruno. Vico.. Joyce”. In: Beckett, Samuel et al. Our Exagmination Round His Factification for Incamination of Work in Progress. Nova York: New Directions, 1972, p. 3-22.

Burgess, Anthony. A Shorter "Finnegans Wake”. Londres: Faber and Faber, 1973.

Campos, Augusto de. "Entrevista com Augusto de Campos no joycentenário". Ilha do Desterro, Florianópolis, Editora da UFSC, n. 12, v. 2, 1984, p. 25-35.

Campos, Haroldo de. Deus e o diabo no Fausto de Goethe. São Paulo: Perspectiva, 1981.

\footnotetext{
24 "The book really has no beginning or end".

25 "each intelligent reader".
} 
Campos, Augusto de; Campos, Haroldo de. Panaroma do Finnegans Wake. São Paulo: Conselho Estadual de Cultura/Comissão de Literatura, 1962.

Campos, Augusto de; Campos, Haroldo de. Panaroma do Finnegans Wake. $4^{\mathrm{a}}$ ed. São Paulo: Perspectiva, 2001.

Eco, Umberto. Six Walks in the Fictional Woods. Cambridge: Harvard University Press, 1995.

Eliot, T. S. “Dante”. Selected Essays. Londres: Faber and Faber, 1934, p. 237-277.

Ellmann, Richard. James Joyce. $2^{\text {nd }}$ ed. Oxford: Oxford University Press, 1983.

Grande Dicionário Houaiss. Disponível em: http://houaiss.uol.com.br . Acesso em 24 de junho de 2019.

Joyce, James. Finnegans Wake. London: Faber and Faber, [1939] 1975a.

Joyce, James. Finnicius revém. Trad. Donaldo Schüler. Cotia: Ateliê Editorial, 1999-2003. 5 vols.

Joyce, James. "Um fragmento de Finnegans Wake". Trad. Caetano Galindo. "Ilustríssima". Folha de São Paulo (24/11/2013). Disponível em: $<$ https://www1.folha.uol.com.br/ilustrissima/2013/11/1374886-um-fragmento-de-finneganswake.shtml $>$. Acesso em 24 de junho de 2019.

Joyce, James. "James Joyce: do Finnegans Wake". Tradução de Caetano Galindo. Circuladô (Ano IV - No 5 - setembro 2016). São Paulo - Poiesis/Casa das Rosas, p. 65-69.

Joyce, James. "Finnegans Wake” por um fio. Tradução de Dirce Waltrick do Amarante. São Paulo: Iluminuras, 2018.

Joyce, James. Ulysses. 1922. Nova York: Vintage, 1986.

Joyce, James. Selected Letters of James Joyce. Richard Ellmann (org.). Nova York: The Viking Press, $1975 \mathrm{~b}$.

Joyce, James; Hoffmeister, Adolf. "The Game of Evenings". Tradução de Michelle Woods. Granta. N No $^{\circ}$ 89, 2005. Disponível em <http://www.granta.com/Archive/89>. Acesso em dezembro de 2013.

Joyce, P. W. English as We Speak It in Ireland. London: Longmans, Green, \& Co., 1910.

Latham, Sean. “A New JJQ Citation Policy”. James Joyce Quarterly, [s.1], Vol. 55, №. 3-4, 2018, p. 277-278.

Lathan, Sean. "A New JJQ Citation Policy". James Joyce Quarterly, [s.1], Vol. 55, No. 3-4, 2018, p. 277-278.

O'connor, Frank. "Portrait of James Joyce". The Spoken Words. Irish Poets and Writers. British Library. Disco 2. 6'14'’. 1996. CD. 
O’Neill, Patrick. Trilingual Joyce. The Anna Livia Variations. Toronto: University of Toronto Press, 2018.

Platt, Len. "Introduction”. Joyce, James. Finnegans Wake. Hertfordshire: Wordsworth, 2012, p. vi-xxv.

Schüler, Donaldo. "Introdução; Notas de Leitura". In: Joyce, James. Finnicius revém. Tradução de Donaldo Schüler. Vol. 1. Cotia: Ateliê Editorial. 1999, p. 15-25; 89-132.

Senn, Fritz. Joycean Murmoirs. Fritz Senn on James Joyce. Edited by Christine O'Neill. Dublin: The Lilliput Press, 2007.

Senn, Fritz; Amaral, Vitor. Entrevista com Fritz Senn. 2019, 24’.

Shorter Oxford English Dictionary. 6. ${ }^{\mathrm{a}}$ ed. Oxford University Press, 2007. CD-ROM.

Slote, Sam. "The Texts of Finnegans Wake: an annotated list of the corrections of misprints". James Joyce Quarterly, Vol. 55, №. 3-4, 2018, p. 405-440.

Steiner, George. "On Difficulty". The Journal of Aesthetics and Art Criticism, no. 3, v. 36, spring, 1978, p. 263-276.

Woods, Michelle. "Introdução". In: Joyce, James; Hoffmeister, Adolf. "The Game of Evenings". Trad. Michelle Woods. Granta. No. 89, 2005. Disponível em $<\underline{\text { http://www.granta.com/Archive/89> }}$. Acesso em dezembro de 2013.

Recebido em: 29 de julho de 2019 Aceito em: 27 de outubro de 2019 Publicado em: Dezembro de 2019 